Cockett, F. B., and Maurice, B. A. (1963). British Medical fournal, 1, 353. D'Abreu, A. L., Rob, C. G., and Vollmar, J. F. (1959). Langenbecks Archiv für klinische Chirurgie, vereinigt mit Deustche Zeitschrift für Chirurgie, $290,52$.

De Bakey, M. E., Crawford, E. S., Cooley, D. A., and Morris, G. C. (1958). Annals of Surgery, 148, 306.

Doberneck, R. C., and Varco, R. L. (1968). Lancet, 88, 143.

Fisher, E. R., and Corcoran, A. (1952). Archives of Internal Medicine, 89, 943. Gosling, R. G., Newman, D. S., Bowden, N. L. R., and Twinn, K. W. (1971). British fournal of Radiology, 44, 850.

Hall, R., and Bunch, G. A. (1971). British fournal of Surgery, 58, 508.

Immon, T. W., and Pollock, B. E. (1956). American Heart fournal, 52, 314.

Laurie, W. (1968). Medical fournal of Australia, 2, 710

Longo, T., and Santa, A. (1971). Fournal of Cardiovascular Surgery, 12, 52.

Magyar, E., Veres, J., and Juhasz, J. (1968). Lancet, 2, 1351.
Pyorala, K., Keikel, P. E., and Halonen, P. I. (1959). American Heart Fournal, 67, 289 .

Pyorala, K., Heinonen, O., Koskelo, P., and Keikei, P. (1960). American fournal of Cardiology, 6, 650 .

Stoerk, E. (1912). Medizinische Klinik, 8, 1227.

Von Ritock, S. (1907). Zeitschrift für klinische Medizin, 61, 32.

Valentine, N., and Nicholl, R. J. (1945). American Heart fournal, 30, 514.

Werley, G., Waite, W. W., and Kelsey, M. P. (1944). Texas State fournal of Medicine, 39, 467.

Womersley, J. R. (1958). Physics in Medicine and Biology, 2, 313.

Wood, P. (1956). Diseases of the Heart and Circulation, 2nd edn., p. 328. London, Eyre and Spottiswoode.

Wright, H. Payling (1968). Nature, 220, 78.

Wright, H. Payling (1970). Thrombosis et Diathesis Haemorrhagica, Suppl. No. 40 , p. 79.

\title{
Fat Embolism in Patients with Fractured Hips
}

\section{SIMON SEVITT}

British Medical fournal, 1972, 2, 257-262

\section{Summary}

Fat embolism was assessed at necropsy and correlated with clinical findings in the patients who died among 854 with fractured hips admitted to hospital between 1967 and August 1971. Sixteen cases of clinical importance were found, eight of which were judged to have been fatal or to have seriously contributed to death. Frequencies were as follows: $2 \cdot 4$ to $3 \cdot 3 \%$ among 424 patients with subcapital fractures; 0.7 to $0.8 \%$ in the 405 with trochanteric fractures; $4 \cdot 1$ to $7 \%$ among subjects treated without operation, representing $30 \%$ of those who died within seven days; and 0.9 to $1.1 \%$ among patients treated by pinning, nailing, or nail-plating. The higher frequency in the conservatively treated group is probably related to selection of poor-risk subjects. Fat embolism was found in 6.8 to $8.0 \%$ of those with subcapital fractures treated by primary Thompson's arthroplasty which utilizes acrylic cement, and in none of those given Moore's prostheses for which cement is not used. Study of a larger group after Moore's prosthesis is required to establish its lack of special risk. Fat embolism accounted for all the deaths within seven days of Thompson's arthroplasty and for most within 14 days; it was clearly related to surgery in some cases.

A possible explanation of the hazard of Thompson's arthroplasty is that fat globule entry is enhanced by a rise of intramedullary pressure due to proximal occlusion of the reamed marrow cavity. A controlled trial of the effect of venting the marrow cavity on the frequency of fat embolism is warranted. It is possible that the acrylic monomer may also contribute to venous entry of medullary fat. The higher-age group of those with subcapital fractures and associated chronic cardiac and pulmonary disease might make them more susceptible to fat embolization than those in whom arthroplasty is also carried out for chronic hip disease.

\section{Introduction}

This study* was undertaken following reports of cardiac arrest or fat embolism, or both, in patients with subcapital fractures

*For the Working Party on Acrylic Cement in Orthopaedic Surgery (Department of Health and Social Security).

Birmingham Accident Hospital, Birmingham 15

SIMON SEVITT, M.D., F.R.C.PATH., Consultant Pathologist, and Honorary Reader in Pathology, University of Birmingham during surgical replacement of the femoral head with Thompson's prosthesis. In this operation polymerizing acrylic cement (methylmethacrylate) is moulded into the reamed marrow cavity of the upper end of the femur and the stem of the titanium prosthesis is embedded therein. Some cases of cardiac arrest were associated with severe pulmonary fat embolism (Burgess 1970; Dandy 1971) or both pulmonary and systemic fat embolism (Gresham and Kuczynski, 1970; Gresham et al., 1971) and others with pulmonary thromboembolism (Phillips et al., 1971), myocardial infarction (Powell et al., 1970), or chronic heart disease. In a prospective study, Gresham et al. (1971) found five patients with fatal fat embolism, including two who died on the operating table, among 32 with subcapital fractures subjected to Thompson's arthroplasty. However, neither fat embolism nor cardiac arrest has been reported after arthroplasty with Moore's prosthesis, for which acrylic cement is not ordinarily used, and few cases have been reported after total hip replacement for chronic arthritic disease with prostheses in which cement is used (Charnley et al., 1971).

Fatal fat embolism has also occurred after prosthetic operations on the knee, with or without the use of cement (Harris, 1970; Norcross, personal communication). Consequently the role of the cement is uncertain. Acute hypotension is also not infrequent during prosthetic hip operations involving the use of cement (Frost, 1970; Powell et al., 1970; Phillips et al., 1971). The origin of the cardiac symptoms and their possible relation to the operation, potential toxicity of the monomer used to polymerize the cement, fat embolism, and natural disease in these elderly subjects are not fully resolved.

This study attempts to assess the risks of fat embolism in patients with various hip fractures, with emphasis on the role of arthroplasty. Assessing the risk of fat embolism and comparing the risks in different groups require strict criteria. Clinical diagnosis was not used, since often it is inaccurate and many diagnoses are overlooked (Sevitt, 1962). Consequently, the assessments were based primarily on a histological search for fat emboli at necropsy. Positive results were collated with the modes of death and other data to help decide those in whom fat embolism caused or contributed to death (fatal cases) and those in whom fat embolism reached clinical significance but was not fatal.

\section{Patients, Material, and Methods}

Frozen sections of lung, kidney, and brain were examined for fat emboli in those who came to necropsy among 854 fractured hip cases admitted between January 1967 and August 1971. The study was retrospective up to December 1970 and prospective after that. To supplement the numbers, tissues were also examined from necropsies in 1966 following Thompson's and Moore's operations. 
Those with hip fractures were listed from the anticoagulant record cards concerned with prophylaxis against thromboembolism, since this is routine in these patients in the Birmingham Accident Hospital and is supervised by the laboratory medical staff (Sevitt, 1968; see Hume et al., 1970). Other records were also used. Case notes and radiographic films were examined to confirm the nature of the fracture, surgical therapy, and other relevant details.

Table I shows the annual numbers of new patients admitted with the different fractures. The 854 subjects consisted of 424 with subcapital (transcervical) fractures, 25 with basal-trans-

TABLB I-Annual Cases

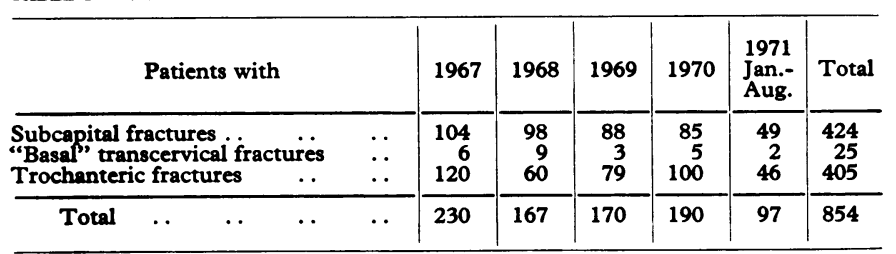

cervical (basal) fractures, and 405 with trochanteric (pertrochanteric, intertrochanteric) fractures. Those with basal fractures were separated because two of their small number developed fatal fat embolism. Elderly women predominated and the mean ages were 75.5 (subcapital), 79.7 (basal), and 77.8 years (trochanteric fractures).

Each patient was under the care of one of six consultant surgeons. The fractures were treated surgically, often by a day or two after injury, unless the clinical state was considered too grave, or in some cases because the fracture was impacted or not displaced. Otherwise, trochanteric and basal fractures were treated routinely by nail-plating, usually Neufeld's or McLaughlin's. Nail-plating was also used for most of the subcapital fractures, though nailing or pinning procedures (SmithPetersen, Newman, or other) were carried out in many impacted fractures and some other cases. The surgeons differed in their use of primary arthroplasty. Two of them almost never used it, and one favoured the Thompson procedure for displaced subcapital fractures; about two-thirds of the primary Thompson operations were done by him. Most of the primary Moore prostheses were carried out by another surgeon. Secondary arthroplastic procedures using Thompson, Moore, metallic Judet, or other prostheses were also employed when previous surgery had been unsatisfactory, usually because of non-union or collapse of the femoral head. Many of these are included in Table I as new cases and are also dealt with as an additional secondary arthroplasty group.

\section{NECROPSIES AND HISTOLOGY}

Available for analysis were records of full postmortem examinations performed by me or a colleague, routine paraffin sections from the lungs, brain, kidneys, and other tissues, and in most cases frozen sections of gelatin-embedded block of brain, kidney, and lung cut at 15 microns and stained with oil-red-0 to demonstrate fat emboli. Frozen sections of myocardium, pituitary, and other organs were made in certain cases. New frozen sections from pieces of brain, kidney, and lung, prepared from tissues kept stored in formol-saline, were examined in 74 patients who died within a month of fracture or surgery. In all those who had survived more than a month fat emboli were few or absent in the lungs and were never seen in the brain or kidney. Degrees of embolism were similar in the old and new preparations of each case. Special myelin preparations to show cerebral ischaemic lesions were used when required.

\section{GRADING OF FAT EMBOLISM}

The grading of fat embolism was based on the frozen sections. In the lung it was assessed as previously recommended (Sevitt,
1962): minor or slight $(+)$, less than 1 embolus per $\times 10$ objective field; moderate $(++), 1$ to 3 emboli; and many $(+++)$, more than 3 emboli per field. Very slight $( \pm)$ and very many $(++++)$ grades were also periodically used. At least 20 fields were counted to assess the mean. Renal and cerebral fat embolism were assessed for systemic involvement. Renal embolism was graded according to the proportion of glomeruli containing emboli-namely, slight $(+)$, less than $10 \%$; moderate $(++), 10$ to $30 \%$; and many $(+++)$, more than $30 \%$ of glomeruli. From 50 to 100 glomeruli were examined. This is a reasonable method of grading, since the average number of emboli per affected glomerulus rises with an increasing proportion of glomeruli affected. Grading of brain embolism $( \pm,+$, and ++$)$ was based on the density of emboli per $\mathrm{cm}^{2}$ of grey matter in the section, combined with evidence of embolic, haemorrhagic, or ischaemic lesions. Cerebellar embolism was found easier to standardize than that in the cerebrum.

\section{Results in Cases of Fat Embolism}

Fat embolism of possible significance was found in 32 necropsies-various grades of both pulmonary and systemic embolism in 30 subjects and moderate lung embolism alone in two. The 32 cases were divided into three groups after correlating the pathological and clinical findings, including the periods of survival after the last exposure to the hazard of embolism. The latter was regarded as the last operation in surgically treated cases, and the accident in those treated conservatively. Rapid collapse was not considered inconsistent with severe fat embolism since fulminating cases after fractures are well recognized, and fat embolism is one of the causes of so-called irreversible traumatic shock (Sevitt, 1962). The three groups are as follows: (1) fatal casesthat is, those in which fat embolism was the sole cause of death or a major contributory cause; (2) symptom-producing cases (referred to as clinical fat embolism); and (3) subclinical fat embolism.

\section{FATAL FAT EMBOLISM (EIGHT CASES)}

Only one case had been suspected clinically (Case 2). Seven were characterized by many pulmonary and systemic fat emboli, a serious clinical episode, and death within three days of exposure. Table II gives details of the four cases which followed Thompson's arthroplasty. One patient (Case 1) died during arthroplasty following slowing of respiration and cardiac arrest associated with driving-in of the prosthesis. Another patient with a subcapital fracture died on the day of the accident without operative intervention. Case 4 had a cardiac arrest during Thompson's arthroplasty and remained in coma until death nine days later. Relatively severe cerebral fat embolism was found, and the lesser degrees of pulmonary and renal embolism were consistent with diminution in numbers of fat emboli during the nine days of survival. Six of the patients had subcapital fractures.

Four cases followed Thompson's arthroplasty (Cases 1 to 4), two followed nail-plating, but the other two patients (with basal fractures) had been treated conservatively. The mean age was 85 years; four were 90 years or older and most had chronic cardiac or pulmonary disease. Four had developed bronchopneumonia. Three of the four cases treated by Thompson's arthroplasty (Cases 1 to 3) are similar to those described by Gresham et al. (1971). Fat embolism, therefore, must be regarded as a cause, though not necessarily the only cause, of cardiac arrest which may occur during Thompson's arthroplasty.

\section{CLINICAL EMBOLISM (EIGHT CASES)}

Fat embolism was not considered to have been important for death, though clinical episodes consistent with this diagnosis were recorded. The mean age was 82 years. Five subjects, 
TABLE II-Fatal and "Clinical" Fat Embolism after Thompson's Arthroplasty for Subcapital Fracture

\begin{tabular}{|c|c|c|c|c|c|c|c|c|c|}
\hline \multirow[b]{2}{*}{ Case } & \multirow[b]{2}{*}{ No. } & \multirow{2}{*}{$\begin{array}{l}\text { Surgery } \\
\text { Time } \\
\text { after } \\
\text { Fracture }\end{array}$} & \multirow{2}{*}{$\begin{array}{l}\text { Sex } \\
\text { and } \\
\text { Age }\end{array}$} & \multirow{2}{*}{$\begin{array}{l}\text { Survival } \\
\text { Time } \\
\text { after } \\
\text { Arthro- } \\
\text { plasty }\end{array}$} & \multirow[b]{2}{*}{ Clinical Notes } & \multicolumn{3}{|c|}{ Fat Embolism } & \multirow[b]{2}{*}{ Other Findings } \\
\hline & & & & & & Lung & $\begin{array}{l}\text { Kidney, } \\
\% \text { Glomeruli } \\
\text { with Emboli }\end{array}$ & Brain & \\
\hline 1 & $\ldots$ & 5 days & F. 73 & $\begin{array}{c}\text { Died during } \\
\text { operation }\end{array}$ & $\begin{array}{l}\text { Breathing slowed as prosthesis } \\
\text { driven in, then stopped; then } \\
\text { cardiac arrest. External } \\
\text { cardiac massage }\end{array}$ & +++ & 50 & + to ++ & $\begin{array}{l}\text { Lung haemorrhage. Myocardial } \\
\text { fat emboli }++\end{array}$ \\
\hline 2 & . & 1 day & F. 84 & 2 days & $\begin{array}{l}\text { cardiac massage } \\
\text { "Clinical" fat embolism. } \\
\text { Postoperative dyspnoea, } \\
\text { delirium, coma. } \\
\text { "Snowstorm"lung } X \text {-ray } \\
\text { picture changes }\end{array}$ & +++ & 72 & ++ & $\begin{array}{l}\text { Lung haemorrhage. Hypertrophy } \\
\text { left ventricle }\end{array}$ \\
\hline 3 & .. & 6 days & F. 90 & 2 days & $\begin{array}{l}\text { Hypotensive and confused night } \\
\text { after operation; later dysp- } \\
\text { noeic, congestive heart failure. }\end{array}$ & $\underset{\substack{+++ \\
\text { marrow }}}{++}$ & 66 & + & $\begin{array}{l}\text { Hypertrophy left ventricle. } \\
\text { Large wound haematoma. } \\
\text { Bronchopneumonia }\end{array}$ \\
\hline 4 & .. & 5 days & F. 77 & 9 days & $\begin{array}{l}\text { Cardiac arrest end of operation; } \\
\text { massage, on to ventilator. } \\
\text { Unconscious. } \mathrm{Po}_{2} 33 \mathrm{~mm} \mathrm{Hg} \text {. } \\
\text { Hyperglycaemia }\end{array}$ & ++ to +++ & 20 & ++ & $\begin{array}{l}\text { Bronchopneumonia. Hyper- } \\
\text { trophy left ventricle. } \\
\text { Myocardial fibrosis. Sclerosed } \\
\text { coronary arteries }\end{array}$ \\
\hline 5 & .. & 3 days & F. 89 & 12 days & $\begin{array}{l}\text { Collapsed day after operation. } \\
\text { Po, } 36 \mathrm{~mm} \text { Hg. O, therapy, } \\
\text { improved. Respiratory } \\
\text { infection. Drowsy, confused, } \\
\text { convulsion }\end{array}$ & + & 5 & \pm & $\begin{array}{l}\text { Bronchopneumonia. "Nutmeg" } \\
\text { liver. Coronary sclerosis. } \\
\text { Hydronephrosis left kidney. } \\
\text { Nephrosclerosis }\end{array}$ \\
\hline 6 & . & 1 day & M. 79 & 14 days & $\begin{array}{l}\text { From } 5 \text { days' postoperative } \\
\text { dyspnoea, tachycardia, } \\
\text { confusion }\end{array}$ & + & 2 & \pm & $\begin{array}{l}\text { Myocardial fibrosis. } \\
\text { Hypertrophy left ventricle. } \\
\text { Coronary sclerosis. Acute } \\
\text { bronchitis. Chronic } \\
\text { emphysema }\end{array}$ \\
\hline $7^{*}$ & . & 7 days & M. 68 & 1 day & $\begin{array}{l}\text { Admitted cyanotic, dyspnoeic. } \\
\text { Postoperative disorientation, } \\
\text { tremor, increased dyspnoea }\end{array}$ & $\begin{array}{c}++ \text { to }++++ \\
\quad \text { (also bone } \\
\quad \text { embolism) }\end{array}$ & 7 & \pm & $\begin{array}{l}\text { Chronic emphysema. } \\
\text { Bronchitis. Hypertrophy left } \\
\text { ventricle. Myocardial } \\
\text { fibrosis }\end{array}$ \\
\hline
\end{tabular}

1966 Case; all others 1967-71

Fatal embolism, Cases 1 to 4. Clinical embolism, Cases 3 to 7.

including Cases 5 and 6 (Table II), had minor or moderate pulmonary and systemic fat embolism. They had survived 7 to 17 days and the degrees of embolism were likely to have been more considerable sooner after operation. Four of them had subcapital fractures, treated by pinning, nail-plating, or Thompson's prosthesis (Cases 5 and 6 ), and the fifth had a trochanteric fracture treated by nail-plating.

Three others, including Case 7, died within two days of operation or fracture with many or moderate numbers of lung fat emboli and only slight systemic embolism. Acute pulmonary symptoms had been recorded in two of them. Lung fat embolism supervening on serious chronic cardiopulmonary impairment may have precipitated acute dyspnoea and thereby contributed to death. These cases have similar features to those described by Dandy (1971) after Thompson's arthroplasty, though two of them had pertrochanteric fractures, one which was not treated surgically.

\section{SUBCLINICAL EMBOLISM (16 CASES)}

Fourteen other subjects had slight systemic fat embolism. In 10 cases lung embolism was also minor, but it was moderate in three others and one patient had many lung emboli. The embolism was not considered to have been clinically important except possibly in one patient referred to later. Ten fractures were subcapital and four trochanteric. Nine had been treated by nailplating (six subcapital), two by Thompson's prosthesis, one by Moore's prosthesis, and two had not been treated by surgery. Five patients had survived between three and seven days, four between one and two weeks, and five for longer than two weeks.

Two other subjects with trochanteric fractures had moderate lung embolism without renal or cerebral emboli. One died three days after without surgical intervention and the other 16 days after nail-plating.

\section{Frequency of Fat Embolism}

The frequency of fat embolism is analysed according to the type of fracture (Table III), operative or non-operative treatment (Tables IV and V), with special reference to arthroplasty (Tables V and VI), and the results are summarized in Table VII. In addition to the observed frequencies, corrected frequencies were calculated, taking into account deaths within 14 days of operation or injury which did not reach necropsy. This period was used because all but one of the patients with significant fat embolism died within 14 days of operation or injury and most within seven days.

TABI.E III-Fat Embolism (F.E.) Related to Type of Fracture

\begin{tabular}{|c|c|c|c|c|}
\hline & Subcapital & Basal & Trochanteric & Total \\
\hline 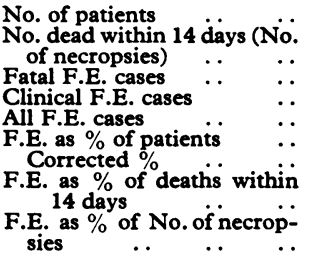 & $\begin{array}{c}424 \\
25(18) \\
6 \\
4 \\
10 \\
2 \cdot 4 \\
3 \cdot 3 \\
40 \\
56\end{array}$ & $\begin{array}{r}25 \\
4(3) \\
2 \\
0 \\
2 \\
8 \\
11 \\
50 \\
67\end{array}$ & $\begin{array}{c}405 \\
33(25) \\
0 \\
3^{*} \\
3^{*} \\
0 \cdot 7 \\
0 \cdot 8 \\
6 \\
8\end{array}$ & $\begin{array}{c}854 \\
62(46) \\
8 \\
7 \\
15 \\
1 \cdot 8 \\
2 \cdot 3 \\
22 \\
30\end{array}$ \\
\hline
\end{tabular}

*One patient died at 17 days, all others within 14 days of exposure.

TABLE IV-Fat Embolism Related sto Conservative Treatment or Pinning, Nailing, or Nail-plating. (All Types of Fracture Combined)

\begin{tabular}{|c|c|c|}
\hline & $\begin{array}{c}\text { No } \\
\text { Operation }\end{array}$ & $\begin{array}{l}\text { Pinning, Nailing, } \\
\text { or Nail-plating }\end{array}$ \\
\hline 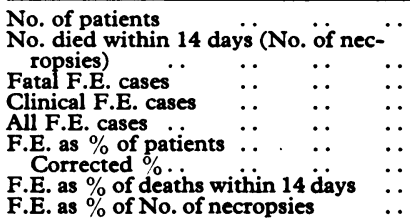 & $\begin{array}{c}73 \\
17(10) \\
2 \\
1 \\
3 \\
4 \cdot 1 \\
7 \cdot 0 \\
18 \\
30\end{array}$ & $\begin{array}{c}669 \\
38(30) \\
2 \\
4^{*} \\
6^{*} \\
0 \cdot 9 \\
1 \cdot 1 \\
13 \\
17\end{array}$ \\
\hline
\end{tabular}

*One patient died at 17 days, all others within 14 days of exposure.

TABLE v-Fat Embolism Related to Primary Surgical Treatment. (Subcapital Fractures 1967-71)

\begin{tabular}{|c|c|c|c|c|}
\hline & \multirow{2}{*}{$\stackrel{\text { No }}{\text { Operation }}$} & \multirow{2}{*}{$\begin{array}{c}\text { Pinning, } \\
\text { Nailing, or } \\
\text { Nail-plating }\end{array}$} & \multicolumn{2}{|c|}{ Primary Arthroplasty } \\
\hline & & & Thompson & Moore \\
\hline 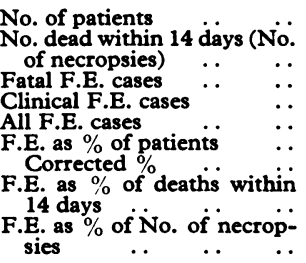 & $\begin{array}{c}35 \\
5(2) \\
1 \\
0 \\
1 \\
3 \\
7 \\
20 \\
50\end{array}$ & $\begin{array}{c}277 \\
13(10) \\
1 \\
2 \\
3 \\
1 \cdot 1 \\
1 \cdot 4 \\
23 \\
30\end{array}$ & $\begin{array}{c}88 \\
7(6) \\
4 \\
2 \\
6 \\
6 \cdot 8 \\
8 \cdot 0 \\
86 \\
100\end{array}$ & $\begin{array}{c}21 \\
0(0) \\
0 \\
0 \\
0 \\
0 \\
0 \\
0 \\
0\end{array}$ \\
\hline
\end{tabular}

All fat embolism patients died within 14 days. 
TABLE VI-Fat Embolism Related to Nature of Prosthesis. Deaths After Primary and Secondary Arthroplasty Combined (1966-71)

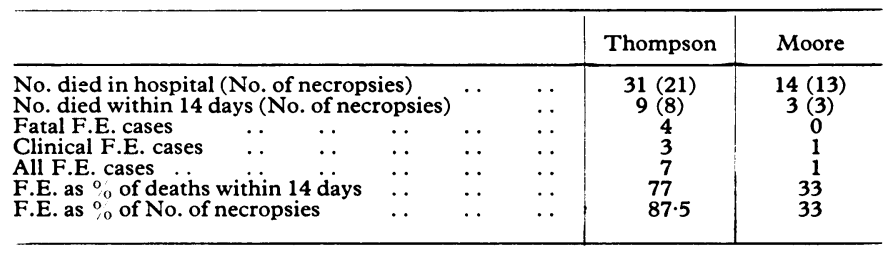

TABLE VII-Summary of Findings

\begin{tabular}{|c|c|c|}
\hline & \multicolumn{2}{|c|}{ Fat Embolism } \\
\hline & Observed $(\%)$ & Corrected $(\%)^{*}$ \\
\hline $\begin{array}{l}\text { Incidence by injury (No. at risk): } \\
\text { All fractured-hip cases (854) } \\
\text { Subcapital fractures }(424) \\
\text { Basal fractures }(25) \\
\text { Trochanteric fractures (405) } \\
\text { Incidence by treatment: } \\
\text { No operation (73) } \\
\text { Pinning, nailing or nail-plating (669) } \\
\text { Subcapital fractures only: } \\
\text { No operation (35) } \\
\text { Pinning, nailing, or nail-plating (277) } \\
\text { Primary Thompson's arthroplasty (88) } \\
\text { Primary Moore's arthroplasty (21) } \\
\text { Primary or secondary Thompson' } \\
\text { arthroplasty (103) } \\
\text { Primary or secondary Moore's arthro } \\
\text { plasty (25) } \\
\text { Deaths within seven days (1966-71): } \\
\text { Thompson's prosthesis (4 necropsies) } \\
\text { Moore's prosthesis (2 necropsies) } \\
\text { Deaths within 14 days (1966-71): } \\
\text { Thompson's prosthesis (9 necropsies) } \\
\text { Moore's prosthesis (3 necropsies) }\end{array}$ & $\begin{array}{c}1 \cdot 8 \\
2 \cdot 4 \\
8 \cdot 0 \\
0 \cdot 7 \\
4 \cdot 1 \\
0.9 \\
3 \cdot 0 \\
1 \cdot 1 \\
6 \cdot 8 \\
0 \\
5 \cdot 8 \\
0 \\
100 \\
0 \\
78 \\
33\end{array}$ & $\begin{array}{c}2.3 \\
3.3 \\
11.0 \\
0.8 \\
7.0 \\
1.1 \\
7 \cdot 0 \\
1.4 \\
8 \cdot 0 \\
0 \\
6.8 \\
0 \\
100 \\
0 \\
87.5 \\
33\end{array}$ \\
\hline
\end{tabular}

*Correction factor $=$ number of deaths divided by number of necropsies.

\section{TYPE OF FRACTURE}

Among 424 cases with subcapital fractures there were 10 with fat embolism $(2 \cdot 4 \%)$, six of which were fatal (1.4\%) (Table III). Among 405 with trochanteric fractures there were three with clinical fat embolism $(0.7 \%)$. These estimates do not take into account possible fat embolism among those not reaching necropsy. Twenty-five patients with subcapital fracture died within 14 days. If the rates of fat embolism are assumed to be similar in the 18 who reached necropsy and the seven who did not, the expected number of cases would be about 14 (correction factor $=$ number of deaths divided by number of necropsies) and the corrected incidence would be $3.3 \%$ in the subcapital series. Among 405 cases with trochanteric fractures there were three cases of fat embolism $(0 \cdot 7 \%)$, two of whom died within 14 days, giving a corrected incidence of $0 \cdot 8 \%$. The fourfold higher frequency among those with subcapital fractures is largely related to the cases treated by Thompson's arthroplasty (see below).

Among those with subcapital fractures, the fat embolism cases made up $40 \%$ of deaths within 14 days and $56 \%$ of the necropsies. These figures are also much greater than those in patients with trochanteric fractures $(6 \%$ and $8 \%)$.

The 25 subjects with basal fractures included two cases of embolism $(8 \%)$, both fatal. They made up half the deaths within 14 days and were the only fatal cases within seven days.

\section{FAT EMBOLISM AND CONSERVATIVE TREATMENT}

Three cases were found among the 73 subjects treated without operative surgery $(4 \cdot 1 \%)$ and the frequency, corrected for the deaths within 14 days which did not reach necropsy, is about $7 \%$ (Table IV). The cases of embolism make up $18 \%$ of the deaths within 14 days and $30 \%$ of the deaths within 14 days which reached necropsy. The three patients had trochanteric, basal, and subcapital fractures respectively. The latter case was found among 35 patients with subcapital fractures treated conservatively $(3 \%)$. In this subgroup only two out of five who died within 14 days reached necropsy, so that the incidence of $3 \%$ may be a serious underestimate. The demonstration that important fat embolism can occur as the sequel to a hip fracture -trochanteric, subcapital, or basal-without surgery does not seem to have been reported hitherto.

\section{FAT EMBOLISM AND NAILING, PINNING, AND NAIL-PLATING}

The 669 subjects consisted of 277 with subcapital fractures, 24 with basal fractures, and 368 with trochanteric fractures. There were six cases of fat embolism (two fatal), giving an overall frequency of $0.9 \%$ and a corrected frequency of $1.1 \%$ (Table IV). The five who died within 14 days of surgery represent $13 \%$ and $17 \%$ of the respective deaths and necropsies. Three cases (one fatal) occurred in the subgroup of 277 subjects with subcapital fractures, giving observed and corrected frequencies of $1.1 \%$ and $1.4 \%$ respectively (Table V). Two of these were among the 195 with nail-plated subcapital fractures $(1 \%)$, and the other was among the 82 with nailed or pinned subcapital fractures $(1 \cdot 2 \%)$. Two cases of fat embolism were found in the subgroup of 368 cases with trochanteric fractures $(0.5 \%)$, all of which were nail-plated, and there was one case among the 24 with nail-plated basal fractures $(4 \%)$.

Fat embolism was more frequent among the conservatively treated cases than in those treated by nailing or nail-plating, but the frequencies among those who died within 14 days are not significantly different. The differences based on total cases cannot be accounted for even by a very high frequency of fat embolism in the eight surgically-treated patients who died within 14 days but did not reach necropsy. The similar percentages among the deaths depend on the fact that the cases of fat embolism in the non-operated group occurred among a greater proportion of early deaths $(20 \%$ within seven days) than was found in the surgically treated group (3\% within seven days). This is not surprising, since many of those not operated on were very ill on admission and had to be treated conservatively. The mean age in this group was $76 \cdot 1$ years but it was 82.2 years among those who died.

\section{ARTHROPLASTY AND FAT EMBOLISM}

One-hundred-and-twelve patients (mean age $78 \cdot 7$ years) with subcapital fractures had a primary arthroplasty, and among them there were six cases of fat embolism $(5.4 \%)$. The corrected frequency was $6.3 \%$. Four patients were judged to have died of embolism (Table II, Cases 1 to 4)-one during operation, two two days later, and the fourth nine days after arthroplasty. The two "clinical" cases in the 1967-71 series died 12 and 14 days respectively after operation (Cases 5 and 6). The fat embolism rate after primary arthroplasty is significantly greater than that after other surgical therapy (nailing, nail-plating, etc.) in patients with subcapital fractures $(P<0.05)$.

\section{THOMPSON'S AND MOORE'S PROTHESES}

Primary arthroplasty with Thompson's prosthesis had been performed in 88 subjects (Table V), with a mean age of 77.9 years. All six cases of fat embolism (four fatal) were found among them, giving an observed frequency of $6.8 \%$ (fatal cases $4.5 \%$ ) and corrected frequencies of $8 \%$ and $5.3 \%$ respectively. These compare with a $16 \%$ incidence of fatal fat embolism among 32 subjects reported by Gresham et al. (1971).

Moore's prosthesis was used in 21 patients (mean age 81.4 years) and Judet's prosthesis in three subjects. Five died, none within three weeks of arthroplasty, and no cases of fat embolism were observed. Nevertheless, the difference in frequency of the proportion of deaths with fat embolism between the Thompson and the Moore groups of subjects does not reach statistical significance because of the small number of patients in the latter group. 
When the 103 patients given primary or secondary Thompson arthroplasty are combined, the observed frequency of fat embolism was $5.8 \%$ (corrected frequency $6.8 \%$ ). On the other hand, there were no deaths within 14 days among the 25 patients after Moore's prosthesis nor among the six after Judet's prosthesis, and no cases of fat embolism were found. The operation notes were examined for records of the use of acrylic cement. Positive records were found in 84 of the 103 Thompson procedures, including the six cases of fat embolism, though the surgeons inform me that acrylic cement had been used in all or at least nearly all of these operations. Among the 25 subjects with Moore's arthroplasty, acrylic cement had been used in one special case. Otherwise, I am informed, cement was never used.

Because of the relatively few cases (and deaths) in the Moore's prosthesis group, the study was extended to include necropsies performed in 1966 (Table VI). This provided one additional case of clinical fat embolism after Thompson's prosthesis (Table II, Case 7). All four subjects who died within seven days of Thompson's arthroplasty had fat embolism. There was also a doubtful case in the Moore's prosthesis group.

Case Report.-Moderate pulmonary and minor systemic (cerebral) fat embolism were observed in a woman of 75 years who died eight days after a secondary Moore's arthroplasty. SmithPetersen nailing had been performed a month previously. Jaundice developed and death was related mainly to a surgical wound infection.

If this very doubtful case is accepted the frequencies of fat embolism among those who died within 14 days was $33 \%$ after Moore's prosthesis (one in three cases) and $78 \%$ (corrected frequency $87.5 \%$ ) after Thompson's prosthesis (seven out of eight or nine cases).

\section{Discussion}

The retrospective nature of most of this study indicates cautious interpretation, but the degrees of fat embolism in the lungs, kidneys, and brain in cases considered to have been fatal were similar to those found in unequivocal cases of severe or fatal fat embolism after other fractures. Consequently, the conclusion cannot be escaped that fat embolism of importance, often fatal, may occur in those with subcapital, basal, or trochanteric fractures, whether or not they receive surgical therapy. The main results are summarized in Table VII. The overall risk of fat embolism among those with pertrochanteric fractures was small, and the higher frequency in the much smaller group of subjects with basal fractures may have been by chance.

A relatively high incidence of fat embolism $(4 \cdot 1$ to $7 \%$ ) was observed in those not operated on, and this might be an underestimate because of the low necropsy rate among the early deaths. This contrasts with the low frequency among those treated by pinning, nailing, or nail-plating $(0.9$ to $1.1 \%)$. This surprising result must depend on case selection since many in the non-operated group were too ill for surgery and some died within a few days of the accident. Attacks of fat embolism may become significant and possibly fatal when the clinical state from natural causes is serious.

The special hazard after Thompson's arthroplasty is confirmed, though the frequency was less than that found by Gresham et al. (1971). Fat embolism was found in 6.8 to $8.0 \%$ of 88 cases after primary Thompson's arthroplasty, and in 5.8 to $6.8 \%$ of 103 subjects after primary or secondary Thompson's arthroplasty. It accounted for all the deaths within seven days of arthroplasty and for all but one of those within 14 days. In contrast, no cases of fat embolism were observed among the deaths of a smaller group of patients given a Moore's prosthesis, none of whom died within 14 days of surgery. The difference between the Thompson and Moore groups is suggestive but does not reach statistical significance because of the small number operated with Moore's prosthesis. A larger series needs to be examined. If the difference is real an explanation is required to explain the special risk after Thompson's arthroplasty.

Liability to important fat embolism is related to clinical factors, like multiple fractures which facilitate venous entry of damaged marrow fat. Susceptibility of certain subjects to lesser amounts of embolic fat might also be involved. Possible factors predisposing to entry of fat globules during Thompson's arthroplasty are reaming of the medullary cavity and its blockage by acrylic cement into which the stem of the prosthesis is embedded, and absorption of the acrylic monomer, which is a fat solvent, might also contribute. Reaming is needed to insert all hip prostheses-Thompson's and Moore's for subcapital fractures, and the McKee-Farrar, Charnley, and allied prostheses for degenerative hip disease. Marrow reaming might be expected to enhance the entry of freed marrow fat globules into torn vessels; reaming of the tibial marrow in rabbits permitted the entry of fat globules into any vessels (Danckwardt-Lillieström et al., 1970). However, fat embolism was not found in patients after Moore's arthroplasty, and this is in accord with the lack of a special risk after intramedullary nailing of long bone fractures (Sevitt, 1962). Marrow reaming might produce fat globule embolism, but there is no real evidence at present that it increases the frequency of fatal embolism or explains the hazard during Thompson's arthroplasty.

Comparison of the postoperative records in the survivors of arthroplasty showed that some had suffered temporary symptoms during the first day or two after surgery, consistent with fat embolism: confusion, drowsiness, dyspnoea, or pyrexia, or a variable combination of symptoms. Similar episodes were recorded after Thompson's and after Moore's arthroplasty but numerical comparison was not possible. Minor symptomatic fat embolism probably occurs after arthroplasty whether or not acrylic cement is used.

\section{USE OF ACRYLIC CEMENT}

Medullary pressure effects from the use of acrylic cement may be important. The cement is firmly packed into the reamed femur and is then wedged by the stem of the prosthesis. A considerable rise in medullary pressure below the cement has been found in vitro and medullary pressures up to $\mathbf{4 . 2}$ atmospheres have been reported (Ohnsorge, 1971). The essential dynamics of fat globule entry into torn vessels is a shift of differential pressure whereby the extravascular pressure rises over that within the vessels, even slightly and momentarily (Young and Griffith, 1950). A considerable rise in extravascular (marrow) pressure is not usual after fractures, and is not essential for fat embolism. Indeed, Whitenack and Hausberger (1971) found in rabbits that intramedullary pressures of only 5 to $10 \mathrm{~cm}$ of water permitted the venous entry of fat injected into the marrow. Nevertheless, when a considerable rise of pressure occurs under special circumstances it might facilitate entry considerably.

The combination of marrow reaming and pressure rise with the use of cement could be determining factors. Venting the reamed marrow by a drill-hole below the cemented prosthesis, or by a tube, was found to reduce considerably the raised medullary pressure compared with that found in unvented cases (Cole, 1971; Ohnsorge, 1971). Consequently, the prophylactic potential of venting the marrow during operation, thereby allowing the escape of blood and fat below the advancing cement, requires investigation, and a controlled trial comparing fat embolism in vented and unvented surgery with Thompson's prosthesis is warranted.

Extremely high intramedullary pressures have also been observed during insertion of the femoral component of the 
McKee-Farrar prosthesis (Cole, 1971). Yet few cases of fat embolism have been reported after total hip replacement for degenerative joint disease with femoral head prostheses embedded into acrylic cement after reaming the marrow. This is in contrast with the episodes after inserting Thompson's prosthesis in concurrent patients with subcapital fractures (Dandy, 1971; Gresham et al., 1971). This has been related to the younger and usually fitter subjects on whom total-hip replacement surgery is carried out, compared with the less fit and older subjects who sustain subcapital fractures. There is evidence that death from fat embolism selects out the elderly (Sevitt, 1962) and this is supported by the high mean ages of the present fatal ( 85 years) and non-fatal cases ( 82 years). This same may be true for patients exposed to the combined risk of marrow reaming and raised marrow pressure.

The statistical help and other useful comments from Professor Sir Richard Doll, F.R.S., and Dr. Richard Peto are gratefully acknowledged.

\section{References}

Burgess, D. M. (1970). British Medical fournal, 3, 588. Charnley, J., Murphy, J. C. M., and Pitkeathly, D. A. (1971). British
Medical fournal, 3, 474.

Cole, P. V. (1971). Report to the Working Party on Acrylic Cement in Orthopaedic Surgery, Department of Health and Social Security. In press.

Danckardt-Lillieström, G., Lorenzi, G. L., and Ollerud, S. (1970). Acta Orthopaedica Scandinavica, Suppl. No. 134.

Dandy, D. M. (1971). British fournal of Accident Surgery, 3, 85.

Frost, P. M. (1970). British Medical fournal, 3, 524.

Gresham, G. A., and Kuczỳnski, A. (1970). British Medical fournal, 3, 465. Gresham, G. A., Kuczynski, A., and Rosborough, D. (1971). British Medical fournal, 2, 617.

Harris, N. H. (1970). British Medical fournal, 3, 523.

Hume, M., Sevitt, S., and Thomas, D. P. (1970). Venous Thrombosis and Pulmonary Embolism. London, Oxford University Press.
.

Ohnsorge, J. (1971). Fournal of Bone and foint Surgery, 53B, 758.

Phillips, H., Cole, P. V., and Lettin, A. W. F. (1971). British Medical fournal, 3, 460 .

Powell, J. N., McGrath, P. J., Lahiri, S. K., and Hill, P. (1970). British Medical fournal, 3,326 .

Sevitt, S. (1962). Fat Embolism. London, Butterworth.

Sevitt, S. (1968). Proceedings of the Royal Society of Medicine, 61, 143.

Whitenack, S. H., and Hausberger, F. X. (1971). American fournal of Pathology, 65, 335.

Young, J. S., and Griffith, H. D. (1950). Fournal of Pathology and Bacterio$\log y, 62,293$.

\section{Phlegm and Filters}

\section{J. RIMINGTON}

British Medical fournal, 1972, 2, 262-264

\section{Summary}

Male mass radiography volunteers aged 40 or more were questioned about their sputum production and cigarette consumption in relation to type (filter or plain) smoked. Of 10,414 volunteers, 3,045 smoked filter cigarettes and 2,393 smoked plain cigarettes. The rate of persistent daily sputum of filter smokers (31.9\%) was significantly lower than that of plain cigarette smokers (37.2\%). A similar pattern was maintained when age and cigarette consumption were standardized. These figures are thought to understate the less injurious nature of filter cigarettes, since more than half of the filter smokers with persistent sputum developed this while previously smoking plain cigarettes.

Whatever the reasons for the less injurious nature of filter cigarettes, it seems that cigarette smokers unable to stop smoking might suffer less from chronic bronchitis if they changed to filter cigarettes.

\section{Introduction}

During the past 15 years there has been a pronounced swing from plain to filter cigarette smoking, and the proportion of cigarette tobacco used in this form has risen from $2.7 \%$ in 1956 to $66 \%$ in 1968 (Todd, 1969). During this time there has been speculation about the protective value, if any, of filter tips in relation to diseases associated with tobacco smoking. Two studies of this problem, investigations into the risk of lung cancer in smokers who switch to filters (Bross and Gibson, 1968; Wynder et al., 1970), suggest that there is some protection as regards lung cancer. The investigations were retrospective in type, and

St. Thomas' Hospital, Stockport

J. RIMINGTON, M.D., Medical Director, Mass Radiography Service, Southern Division, Manchester Regional Hospital Board it was in order to lay the foundations for a prospective study of the same matter that much of the information used in this paper was collected, the object being to relate the type of cigarette smoked to lung cancer incidence over a period of years. The collection of the data, however, also gave an opportunity to determine the prevalence of persistent sputum among the cigarette smokers of the sample.

With information on sputum production to hand it has been possible to relate it to the type of cigarette smoked, and the results are reported in this paper. The definition of persistent sputum for the purposes of this study is the production of phlegm from the chest during the last two years, either on most days of the year or on most days for at least three months of the year.

\section{Material and Methods}

The data were obtained during 1970 and 1971 by questioning men, from industry and the general public, who volunteered for mass radiography examination and who were aged at least 40 .

After recording the age, address, and other identification details of each volunteer, a smoking history was taken which included the type (filter or plain), the amount, the manner, and the duration of cigarette smoking. A cigarette smoker was defined as one who had smoked at least one cigarette daily for as long as a year, and those who had stopped smoking at least two weeks before attending the radiography unit were classed as ex-smokers. Hand-rolled cigarette smokers were counted as plain or filter smokers according to whether or not filter-tips were inserted, and the amount of tobacco used was converted to cigarette equivalents $(1 \mathrm{oz}(28 \mathrm{~g})$ a week $=4$ cigarettes a day). Mixed smokers (those smoking as much as 1 cigar a week or $1 \mathrm{oz}(28 \mathrm{~g})$ of pipe tobacco a month in addition to their cigarettes) were excluded from the investigation.

Each volunteer was asked if he brought up or coughed up phlegm from his chest, and, if so, whether or not he did this on most days of the year or on most days for at least three months of the year and for how many years he had done this. Chest - $x$-ray films on $100 \mathrm{~mm}$ film were taken and any significantly 